\title{
Environmental fate and behavior of persistent organic pollutants in Shergyla Mountain, southeast of the Tibetan Plateau of China
}

\author{
Nali Zhu ${ }^{\text {a }}$, Karl-Werner Schramm ${ }^{\text {b,c }}$, Thanh Wang a , Bernhard Henkelmann ${ }^{\text {b }}$, \\ Xiaoyan Zheng ${ }^{\text {a,d }}$, Jianjie Fu ${ }^{a}$, Yan Gao ${ }^{\text {a }}$, Yawei Wang ${ }^{\mathrm{a}, \mathrm{b}, *}$, Guibin Jiang ${ }^{\mathrm{a}}$ \\ a State Key Laboratory of Environmental Chemistry and Ecotoxicology, Research Center for Eco-Environmental Sciences, Chinese Academy of Sciences, \\ Beijing 100085, China \\ ${ }^{\mathrm{b}}$ Molecular EXposomics (MEX), Helmholtz Zentrum München - German Research Center for Environmental Health (GmbH), Ingolstädter Landstrasse 1, \\ 85764 Neuherberg, Germany \\ ${ }^{\mathrm{c}}$ Weihenstephan für Ernährung und Landnutzung, Department für Biowissenschaften, Wissenschaftszentrum, TUM, Weihenstephaner Steig 23, \\ 85350 Freising, Germany \\ d China National Environmental Monitoring Center, Beijing 100012, China
}

\section{A $R$ R T I C L E I}

\section{Article history:}

Received 16 December 2013

Received in revised form

22 April 2014

Accepted 23 April 2014

Available online 20 May 2014

\section{Keywords:}

POPs

Environmental behaviors

Air

Mountain

Tibetan Plateau

\begin{abstract}
A B S T R A C T
Pristine mountains are ideal settings to study transport and behavior of persistent organic pollutants (POPs) along gradients of climate and land cover. The present work investigated the concentrations and patterns of 28 organochlorine pesticides (OCPs), 25 polychlorinated biphenyl (PCBs), 13 polybrominated diphenyl ethers (PBDEs), and 3 hexabromocyclododecane (HBCDs) isomers in the air of the Shergyla Mountain, southeastern Tibetan Plateau. Endosulfan I, hexachlorobenzene, pentachlorobenzene, hexachlorocyclohexanes and dichlorodibenzotrichloroethane and its degradation products (DDTs) were the predominant compounds while PBDEs and HBCDs showed the lowest background concentrations. Most of the target POPs had significantly higher concentrations in summer than those in winter. Increasing trends of the concentrations of DDTs and endosulfan were found with increasing altitude on the western slope in the Shergyla Mountain. Potential forest filter effect was observed based on the lower air concentrations of the target POPs in the forest than the ones out of the forest.
\end{abstract}

(c) 2014 Elsevier Ltd. All rights reserved.

\section{Introduction}

Persistent organic pollutants (POPs) are chemical substances that persist in the environment, bioaccumulate through the food web, and pose a risk of causing adverse effects to humans and the ecosystem. With the evidence (Cabrerizo et al., 2012; Estellano et al., 2008; Wang et al., 2009) of long-range atmospheric transport (LRAT), these compounds can reach pristine areas where they are never used or produced, such as high latitude or altitude regions. Organochlorine pesticides (OCPs), polychlorinated biphenyls (PCBs), polybrominated diphenyl ethers (PBDEs) and hexabromocyclododecanes (HBCDs) are four categories of POPs under the Stockholm Convention. Most of OCPs were introduced to the large-scale commercial production and use since 1950s and they have been totally prohibited in the year of 1983 in China. PCBs and PBDEs are both industrial chemicals and share many similar

\footnotetext{
* Corresponding author

E-mail address: ywwang@rcees.ac.cn (Y. Wang).
}

physicochemical properties. They have been ubiquitously found in the environment in the worldwide. As one of the most used brominated flame retardants, HBCDs have just been listed into Stockholm Convention as a new POPs in 2013.

Passive air samplers (PAS) are widely used for investigating the concentrations, distribution patterns and transport mechanisms of POPs in atmospheric environments. Compared to active air samplers, PAS are relatively simple, low-cost, and free of a power supply. The common used sampling media equipped with PAS includes semi-permeable membranes, polyurethane foam and XAD resins. Thereinto, XAD-based PAS shows higher uptake capacity and can be deployed for longer sampling periods (Wania et al., 2003) for gas phase concentrations of OCPs (Schrlau et al., 2011), PCBs (Shen et al., 2006; Wang et al., 2010), PBDEs (Shen et al., 2006; Wang et al., 2010) in various areas, especially in high altitude regions and remote areas. In the mountain areas, specific mountain conditions (e.g., elevation and topographical gradients) and climate conditions (e.g., variation of temperature and precipitation) strongly affect the environmental behavior of POPs (Daly and Wania, 2005), and make the contaminant fate different from that in neighboring lowlands. 


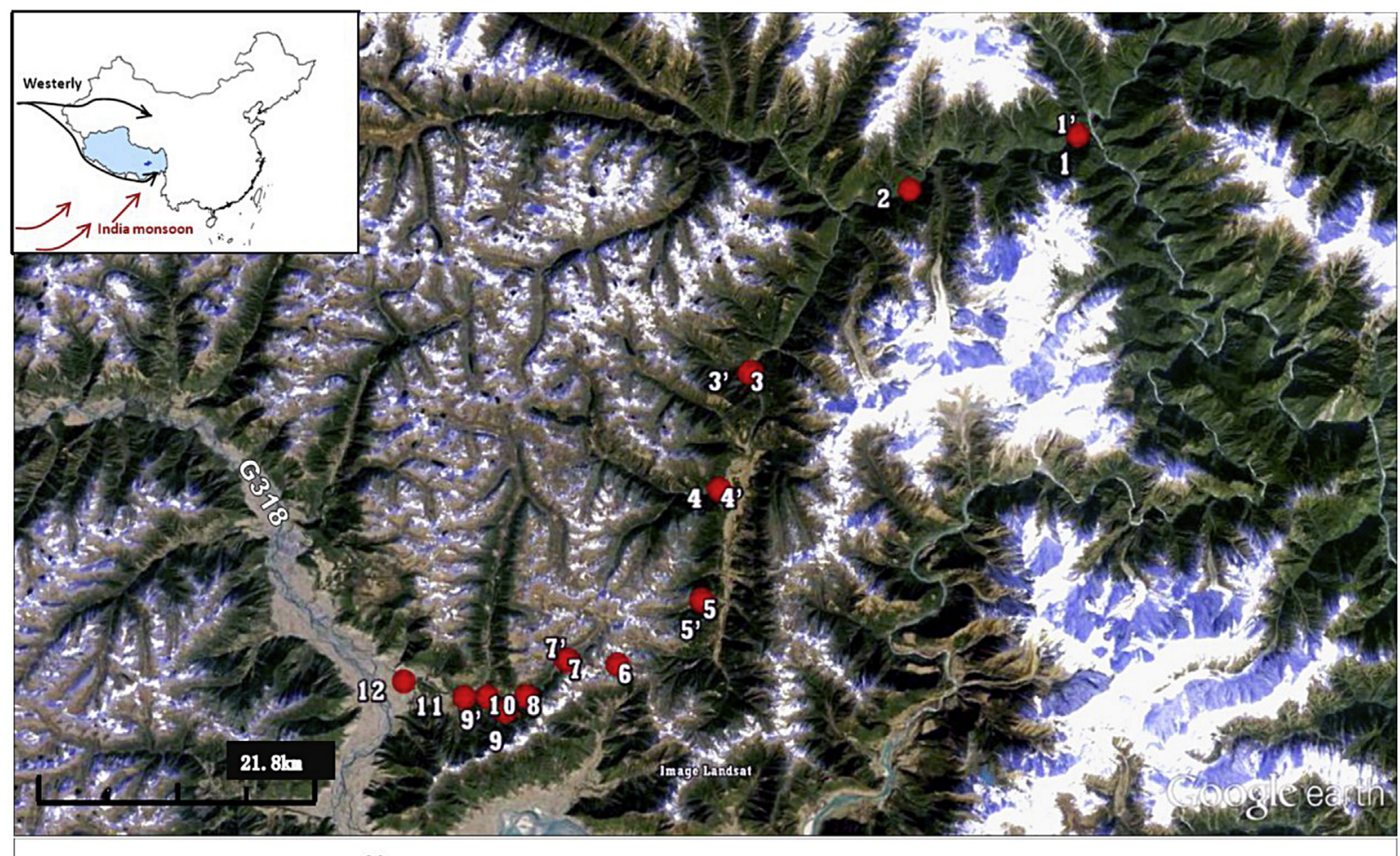

s6

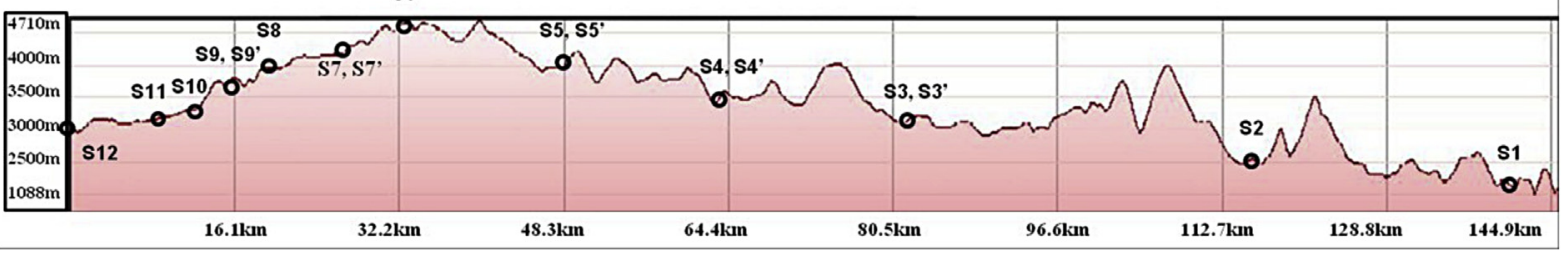

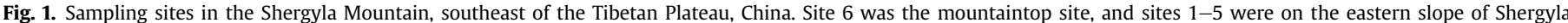

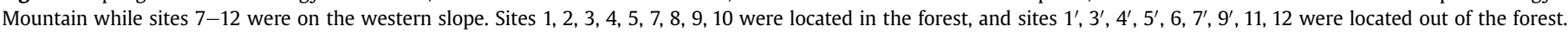

Often called the roof of the world (with an average altitude of $4000 \mathrm{~m}$ above sea level), the Tibetan Plateau lies north of the Himalayas and is one of the coldest and most pristine regions in the world. On accounting of the sparse human population and minimal to nonexistent industrial activities, most of POPs have no perceivable local sources in this high mountain region except for some OCPs (Li et al., 2008). Atmospheric transport is considered to be the most important approach for external source of POPs and novel organic pollutants to the Tibetan Plateau (Gong et al., 2010; Wang et al., 2008; Xiao et al., 2012). Previous works have found that POPs and other contaminants might particularly exist in the plateau due to the orographic cold-trapping effect (Liu et al., 2010; Wang et al., 2009; Yang et al., 2008). Shergyla Mountain is located in southeast of the Tibetan Plateau and is one of the main forest zone in the Tibetan Plateau. Due to the variable impact of the large moisture passage of the Yarlung Tsangpo Valley and the mountain block, the eastern and western slopes of the Shergyla Mountain show obviously different climates. The rainfall on the eastern slope (about $1000 \mathrm{~mm}$ per year) is about $40 \%$ higher than that of the western slope.

The purpose of the present work is to investigate the air concentrations of OCPs, PCBs, PBDEs, and HBCDs by XAD-PAS along elevation gradients in Shergyla Mountain, further to study the possible transport mechanism of target POPs under the influence of various environmental parameters i.e., temperature, precipitation, monsoon and vegetation. It is expected that the study will gain insight into the source, atmospheric transport and cold-trapping/ condensation effect of POPs in the atmosphere in this high mountain area. Investigations on the atmospheric concentrations of HBCDs in remote environments are very scarce. The only available researches for background levels of HBCDs originated from Europe and the United States and used active air samplers to measure HBCDs air concentrations for repeated short-periods (Hoh and Hites, 2005; Remberger et al., 2004). To our knowledge, this was the first work to provide the background levels of HBCDs in the high mountain areas of the Asia region.

\section{Experimental section}

2.1. Sampling

The sampling was carried out in the Shergyla Mountain, southeast of the Tibetan Plateau during the period of July 2010 to May 2011 (Fig. 1). The altitude of the sampling sites ranged from 1983 to $4553 \mathrm{~m}$ above sea levels, with steep gradients at the mountain sides. Considering the influence of the snowstorm on the sampling, XAD-2 PAS were deployed for two time-integrated sampling periods, including a 4month summer period (July-October, 2010) and a 7-month winter period (November of 2010-May of 2011). Sampling sites are located on the eastern and western slopes of the Shergyla Mountain. The sampling inside the forest and corresponding outside the forest was also concerned to investigate the potential forest filter effect. In all, 36 air samples were collected. Triplicate blanks were also prepared by fixing the XAD-2 resin-filled stainless mesh cylinder into the sampler housing during the sampling. The assemblage and use information of XAD-2 resin based PAS has previously been described in details (Zheng et al., 2010). The samples were stored in insulation ice boxes (polyester) and immediately taken back the laboratory 
after sampling. Anhydrous sodium sulfate was included as one blank in this procedure.

\subsection{Sample preparation}

Two different pretreatment methods reported previously (Botaro et al., 2011; Wang et al., 2009; Zhu et al., 2012) were used to analyze the four groups of POPs (OCPs, PBDEs, PCBs and HBCDs) in this work. The detailed description about the pretreatment can be found in the Supporting Information.

\subsection{Instrumental analysis}

Isotope-dilution method was used to analyze all the target compounds. 28 pesticides $(\alpha-\mathrm{HCH}, \beta-\mathrm{HCH}, \gamma-\mathrm{HCH}, \delta-\mathrm{HCH}, \varepsilon-\mathrm{HCH}$, pentachlorobenzene, hexachlorobenzene, pentachloroanisole, octachlorostyrene, 4,4'-DDT, 2,4'-DDT, 4,4'DDD, 2,4'-DDD, 4,4'-DDE, 2,4'-DDE, trans-chlordane, cis-chlordane, oxy-chlordane, heptachlor, cis-heptachloroepoxide, trans-heptachloroepoxide, aldrin, dieldrin, endrin, endosulfan I, endosulfan II, methoxychlor and mirex) were determined by an Agilent 5890 gas chromatograph coupled with a Finnigan MAT 95 mass spectrometer. Chromatographic separation of analytes was performed on a ZB-MultiResidue 2 column (length of $30 \mathrm{~m}$, ID of $0.25 \mathrm{~mm}$ and $0.2 \mu \mathrm{m}$ film thickness). The GC oven settings were as follows: initial temperature $80{ }^{\circ} \mathrm{C}$, held for $1.5 \mathrm{~min}$, then at $10^{\circ} \mathrm{C} \mathrm{min}^{-1}$, increased to $320^{\circ} \mathrm{C}$ and held for $7 \mathrm{~min}$. Ionization mode of $\mathrm{EI}(47 \mathrm{eV}$, $260{ }^{\circ} \mathrm{C}$ ) was chosen for MS; resolution $>8000$ and SIM mode was chosen for detection. The 13 PBDE congeners (BDE-17, 28, 47, 66, 71, 85, 99, 100, 138, 153, 154, 183 , and 190) and 25 PCB congeners, consisting of 12 dioxin-like congeners (CB-77, $81,105,114,118,123,126,156,157,167,169$, and 189), 6 indicator congeners (CB-28, $52,101,138,153$, and 189), and other congeners (CB-3, 15, 19, 202, 205, 208, and 209) were quantified using an HRGC/HRMS (Agilent 6890N/AutoSpec Ultima) system. For determination of the three HBCD isomers $(\alpha-, \beta-, \gamma$-HBCD), a high performance liquid chromatography (Waters 2695) coupled to a triple-quadrupole mass spectrometer (Waters Micromass) was employed. Detailed information about instrument configuration, operational procedures and conditions for PBDEs, PCBs and HBCDs were reported elsewhere (Feng et al., 2010; Wang et al., 2009).

\subsection{Quality assurance/quality control}

Procedure validation was ensured using isotope-dilution method. Laboratory blanks were included in the analysis and processed in parallel with each batch of 11 samples. The mean recoveries of ${ }^{13} \mathrm{C}$-labeled OCPs internal standards, 68C-LCS (for PCBs), ${ }^{13} \mathrm{C}$-labeled PBDEs internal standards, and ${ }^{13} \mathrm{C}_{12}-\gamma$-HBCD were $80 \pm 13 \%$, $80 \pm 23 \%, 61 \pm 6 \%$, and $91 \pm 13 \%$, respectively. Mean limits of detection (LOD) of the analytical method, calculated as signal-to-noise ratio $(\mathrm{S} / \mathrm{N})=3: 1$, for OCPs, PCBs, PBDEs and HBCDs were $3.89 \pm 2.14,0.21 \pm 0.19,0.33 \pm 0.21$, and $54.8 \pm 23.5 \mathrm{pg} / \mathrm{PAS}$ for XAD-2 resins. The limits of quantification were defined at a signal to noise ratio of 10:1 except for OCPs which was at 9:1. The result data were adjusted using blank values: result value $R=$ sample value - average blank value $X$. If the result value $R$ is larger than 3 times standard deviation of mean blank value $X$, the value $R$ is valid and reported as a result. Otherwise $R$ is treated as not detectable.

\section{Results}

\subsection{Airshed calculation}

Six-day back trajectories arriving at the coordinates of the sampling sites were calculated at $500 \mathrm{~m}$ above ground level at $6 \mathrm{~h}$ intervals for every 3 days of the sampling periods (from July 2010 to October 2010 (summer) and from November 2010 to May 2011 (winter)). The model was based on the Hydrid Single Particle Lagrangian Integrated Trajectory Model (HYSPLIT) of the National Oceanic and Atmospheric Administration of the United States. The back trajectory probability maps were showed in Fig. S1 in supporting information. The back trajectory probability maps of the two slopes showed very similar airshed, which might be due to the coordinates spacing of the sampling sites between the eastern and western slope was very small and close to the grid resolution of the model. On the whole, the sampling region of the Shergyla Mountain was mainly influenced by two kinds of air current, one coming from south Asia predominant in the summer and the other coming from southwest Asia predominant in the winter.

\subsection{Volumetric air concentrations calculation}

In this study, the concentration of hexachlorobenzene (HCB) was quite constant, with a variation coefficient value of $36 \%$, which was consistent with the results in other studies (Liu et al., 2010; Su et al., 2006). Previous work has pointed out that compared to other POPs, HCB is very resistant to attack by photo-oxidants (Brubaker and Hites, 1998) and has relatively high volatility (vapor pressure: $1.80 \mathrm{E}-05 \mathrm{~mm} \mathrm{Hg}$ ) to avoid efficient dry particle and wet deposition, thus has an exceptionally long atmospheric residence time in excess of one year. So it has been used as a reference compound to obtain a series of sampler-specific constant sampling rates $R$ based on its constant amount in a certain region, further to convert the PAS-based amounts into volumetric air concentrations (Liu et al., 2010). In this study, an average air concentration value of $56 \mathrm{pg} \mathrm{m}^{-3}$ for HCB was assumed to prevail in the air of the Shergyla Mountain throughout the sampling year (Liu et al., 2010; Su et al., 2006), which is also consistent with those in rural/ background sites in Western China (Cheng et al., 2007) and the representative value of $\mathrm{HCB}$ air level in Northern hemispheric background conditions (Barber et al., 2005; Su et al., 2006). The average sampler specific sampling rates $R$ calculated in present study was $2.71 \pm 0.77 \mathrm{~m}^{3}$ day $^{-1}$ and close to the $R$-values determined previously in the Tibetan Plateau (Liu et al., 2010; Wang et al., 2010).

\subsection{Levels and profiles of POPs in air}

Detection frequencies of $\varepsilon-\mathrm{HCH}$, octachlorostyrene, 4,4'-DDD, trans-chlordane, cis-chlordane, oxy-chlordane, heptachlor, transheptachloroepoxide, aldrin, endrin, methoxychlor and mirex were less than $50 \%$ in the samples, and their concentrations were at very low levels, thus they were not included in the discussion. In all, 16 OCPs, 25 PCBs, 13 PBDEs and 3 HBCDs in this work were finally reported. By dividing the concentration of HCB in each XAD-based sampler, the volume of the air samples were calculated and the converted volumetric air concentrations of POPs were presented in Table 1 . The result indicated that concentrations of endosulfan I, $\mathrm{HCB}$ and pentachlorobenzene were highest among the target compounds, followed by HCHs, DDT and PCBs. PBDEs and HBCD presented at lowest levels. The mean value of Endosulfan I was $78.0 \mathrm{pg} \mathrm{m}^{-3}$ in the air of the Shergyla Mountain and the ratios of endosulfan $\mathrm{I} / \mathrm{II}$ ranged from 16.2 to 84.5 (mean value of 44.5 ). DDTs was detected in all samples with a mean concentration of $15.2 \mathrm{pg} \mathrm{m}^{-3} 2,4^{\prime}$-DDT and 4,4'-DDT were the major components accounting for $54.3 \%$ (ranging from 39.8 to $63.6 \%$ ) and $25.5 \%$ (ranging from 17.7 to $41.1 \%$ ) of $\sum D D T s$, respectively. Concentration ratios of $2,4^{\prime}$-DDT/4, $4^{\prime}$-DDT, $2,4^{\prime}$-DDT/(2,4'-DDD $\left.+2,4^{\prime}-\mathrm{DDE}\right)$ and $4,4^{\prime}$-DDT/(4, $4^{\prime}$-DDD $+4,4^{\prime}$-DDE) ranged from 0.97 to 3.05 (mean of 2.27 ), 4.5 to 16.3 (mean of 9.0 ) and 0.6 to 3.1 (mean of 1.9 ), respectively. The average concentration of $\sum \mathrm{HCHs}$ was $21.2 \mathrm{pg} \mathrm{m}^{-3}$. Among which, $\alpha$ - and $\gamma$-HCH were the dominant congeners with mean percentage of $74.5 \%$ and $18.2 \%$ of $\sum \mathrm{HCH}$ respectively, followed by $\beta-\mathrm{HCH}(6.47 \%)$ and $\delta-\mathrm{HCH}(0.87 \%)$. The ratio of $\alpha-\mathrm{HCH} / \gamma-$ $\mathrm{HCH}$ ranged from 2.0 to 6.9 (mean 4.4 ).

PBDEs and PCBs could be found in all samples whereas the detection frequency of HBCDs was 55.5\% among all the samples. The average concentration of $\sum{ }_{13} \mathrm{PBDEs}, \sum_{3} \mathrm{HBCD}$ and $\sum_{25} \mathrm{PCBs}$ in the air was $0.08,0.25$ and $0.86 \mathrm{pg} \mathrm{m}^{-3}$, respectively (Table 1 ). TetraBDEs represented $41.5 \%$ of the total PBDEs, followed by tri-BDEs (25.7\%), penta-BDEs (12.1\%), hepta-BDEs (10.8\%) and hex-BDEs (9.7\%). BDE183 was the third dominant congener with proportion of $11.0 \%$ after BDE47 (33.1\%) and BDE28 (17.7\%). Indicator PCBs, dioxin-like PCBs and CB209 accounted for $84.4 \%, 5.6 \%$ and $0.6 \%$ of $\sum_{25} \mathrm{PCB}$, respectively. $\mathrm{CB} 28$ was the most predominant congener with proportion of $43.2 \%$, followed by CB52 and CB138. As expected, relatively higher concentrations with lighter congeners were observed in the 25 PCB congener profiles with the following order: tri-CBs $(44.6 \%)>$ tetra-CBs $(21.6 \%)>$ penta-CBs 
Table 1

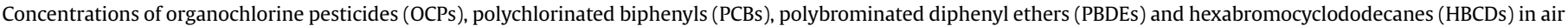
samples.

\begin{tabular}{|c|c|c|c|c|c|c|c|c|c|}
\hline & Mean & Median & Min & Max & \multirow[t]{2}{*}{$\mathrm{DF}^{\mathrm{a}}(\%)$} & Mean & Median & Min & \multirow[t]{2}{*}{ Max } \\
\hline & \multicolumn{4}{|c|}{$\left(\mathrm{pg} / \mathrm{m}^{3}\right)$} & & \multicolumn{3}{|c|}{ (pg/g PAS/day) } & \\
\hline$\alpha-\mathrm{HCH}$ & 15.7 & 15.5 & 8.12 & 29.3 & 100 & 1.39 & 1.25 & 0.40 & 2.71 \\
\hline$\beta-\mathrm{HCH}$ & 1.45 & 1.15 & n.d. ${ }^{b}$ & 7.50 & 86.1 & 0.12 & 0.10 & 0.06 & 0.68 \\
\hline$\gamma-\mathrm{HCH}$ & 3.89 & 3.54 & 2.39 & 8.18 & 100 & 0.37 & 0.33 & 0.10 & 1.20 \\
\hline$\delta$-HCH & 0.20 & 0.13 & n.d. & 0.91 & 94.4 & 0.02 & 0.02 & n.d. & 0.08 \\
\hline$\sum \mathrm{HCH}$ & 21.2 & 20.5 & 12.4 & 40.5 & 100 & 1.90 & 1.80 & 0.57 & 3.87 \\
\hline $4,4^{\prime}-\mathrm{DDT}$ & 3.87 & 3.48 & 0.93 & 9.09 & 100 & 0.37 & 0.26 & 0.06 & 1.19 \\
\hline $2,4^{\prime}$-DDT & 8.23 & 8.10 & 2.59 & 15.2 & 100 & 0.77 & 0.59 & 0.14 & 2.19 \\
\hline $2,4^{\prime}-\mathrm{DDD}$ & 0.24 & 0.19 & 0.05 & 0.71 & 100 & 0.02 & 0.02 & n.d. & 0.14 \\
\hline $4,4^{\prime}-\mathrm{DDE}$ & 2.11 & 2.02 & 0.66 & 5.17 & 100 & 0.21 & 0.16 & 0.03 & 0.64 \\
\hline $2,4^{\prime}-\mathrm{DDE}$ & 0.72 & 0.66 & 0.27 & 1.39 & 100 & 0.07 & 0.05 & 0.01 & 0.25 \\
\hline$\sum \mathrm{DDT}$ & 15.2 & 14.5 & 5.09 & 31.1 & 100 & 1.44 & 1.10 & 0.25 & 3.98 \\
\hline Endosulfan I & 78.0 & 79.2 & 33.9 & 126 & 100 & 7.00 & 6.25 & 2.12 & 15.7 \\
\hline Endosulfan II & 2.08 & 1.77 & 0.54 & 4.56 & 100 & 0.19 & 0.16 & 0.03 & 0.53 \\
\hline Pentachlorobenzene & 24.9 & 23.9 & 13.8 & 61.5 & 100 & 2.12 & 2.07 & 1.04 & 4.32 \\
\hline Hexachlorobenzene & 56 & 56 & 56 & 56 & 100 & 5.05 & 4.89 & 2.04 & 9.26 \\
\hline Pentachloroanisole & 4.86 & 5.00 & 0.93 & 19.7 & 100 & 0.48 & 0.36 & 0.05 & 1.55 \\
\hline cis-heptachloroepoxide & 0.06 & 0.06 & n.d. & 0.16 & 83.3 & 0.01 & 0.01 & n.d. & 0.02 \\
\hline Dieldrin & 0.36 & 0.33 & n.d. & 0.79 & 94.4 & 0.03 & 0.03 & n.d. & 0.12 \\
\hline$\sum_{13} \mathrm{PBDE}$ & 0.08 & 0.08 & n.d. & 0.26 & 100 & 0.01 & 0.01 & 0.00 & 0.02 \\
\hline$\sum_{25} \mathrm{PCB}$ & 0.86 & 0.71 & 0.22 & 2.15 & 100 & 0.08 & 0.07 & 0.03 & 0.23 \\
\hline$\sum_{3} \mathrm{HBCD}$ & 0.25 & 0.01 & n.d. & 2.84 & 55.5 & 0.04 & 0.01 & n.d. & 0.29 \\
\hline
\end{tabular}

a Detection frequency.

b Not detectable; PAS, sampling media of the passive air sampler, here means the XAD-2 resin.

$(15.7 \%)>$ hexa-CBs $(9.5 \%)>$ di-CBs $(7.7 \%)>$ de-CBs $(0.6 \%)>$ nonaCBs $(0.2 \%)$. With regard to HBCDs, $\gamma$-HBCD dominated in the HBCD profile and contributed to $84.9 \%$ of $\sum_{3} \mathrm{HBCD}$ while $\alpha$-HBCD and $\beta$ HBCD were at $9.1 \%$ and $6.0 \%$, respectively.

\subsection{Occurrence of POPs in various environmental conditions}

The occurrence of the target POPs in different seasons in the sampling regions was shown in Fig. 2. Concentrations of DDTs, pentachloroanisole, PBDEs, HBCDs and PCBs in summer were significantly (Paired-samples $T$ Test, $p<0.05$ ) higher than those in winter. HCHs in the two seasons showed comparable levels but the mean ratio of $\alpha-\mathrm{HCH} / \gamma-\mathrm{HCH}$ in winter and summer was 5.0 and 3.9, respectively. Endosulfan I showed significantly higher levels in winter than those in summer $(p<0.05)$, whereas endosulfan II showed opposite trend. Seasonal correlation analysis (bivariate correlation analysis for each individual compounds) indicated that there was no significant correlation $(p>0.05)$ between the air concentrations of target compounds in the summer and in the winter.

Different POPs concentration trends with altitudinal gradient were observed on the western slope and eastern slope of the Shergyla Mountain (Fig. 3). Generally, the concentrations of the target POPs remained stable on the eastern slope along altitudinal gradients except endosulfan II in winter, where the levels decreased significantly $(p<0.05)$ with the altitude. Different from the eastern slope, clear concentration gradients of POPs with altitude were obtained on the western slope. Concentrations of DDTs and endosulfans in the air increased by about 2-3 times from $3035 \mathrm{~m}$ above sea level (a.s.l.) to $4553 \mathrm{~m}$ a.s.l. on the western slope. Correlation analysis revealed that concentrations of $4,4^{\prime}$-DDT and $2,4^{\prime}$-DDT had significantly positive relationships with altitude $(p<0.05)$, and the regression slope of 2,4'-DDT was higher than the one of 4,4'-DDT (Fig. 3). On the contrary, concentrations of HBCDs, HCHs, PBDEs, pentachlorobenzene and pentachloroanisole showed negative relationships with elevation. For PCBs, the concentrations showed negative relationship with altitudes in summer whereas positive relationship in winter.
Forest filter effect for the target compounds was also concerned by comparing the concentrations in the forest and out of the forest. Most of the target POPs, except for dieldrin and $\sum$ endosulfan in winter, showed lower air concentrations in the forest than that in adjacent clearings (Fig. 4). Especially for $\sum$ endosulfan, $\sum \mathrm{HCH}$, and $\sum$ PCB in summer. On the whole, at low altitudes ( $<3300 \mathrm{~m}$ ), where both broadleaf forests and deciduous-coniferous forests exist, ratios of the forest:clearing concentrations of most POPs (except for HBCDs, PBDEs and dieldrin) in the summer were in the range of 0.51 , whereas the ones in winter were about 1 or even higher than 1 .

\section{Discussion}

\subsection{Potential sources of POPs}

Generally, concentrations of the target POPs in the air of the Shergyla Mountain were at the relatively low levels (Table 1). Most of the target OCPs levels in the Shergyla Mountain were about 10 times lower than those in urban areas of Lhasa (Li et al., 2008) and in the Bolivian Andes Mountains (Estellano et al., 2008), about 10100 times lower than those in Beijing (Li et al., 2009), and 1001000 times lower than those in India (Zhang et al., 2008). The levels of PCBs, PBDEs and HBCDs were comparable to the observations from other background and remote areas in the worldwide (Baek et al., 2011; Eleni et al., 2009; Remberger et al., 2004; Su et al., 2007).

Though endosulfan is currently listed in the Stockholm Convention on POPs, they are still in use in many countries including China. Compared to the reports at other regional background and global alpine sites (Pozo et al., 2006), the air concentration of endosulfan I in the Shergyla Mountain was at a very low level. However its relative prevailing level in the air of the Shergyla Mountain still matched the conclusion that endosulfan was one of the most abundant OCPs in the global air (Weber et al., 2010). The ratios of endosulfan I/II (16.2-84.5) in the air of the Shergyla Mountain were 2-3 times higher than those in the technical mixture (Estellano et al., 2008), which might be due to the conversion of endosulfan II to endosulfan I in the environment 


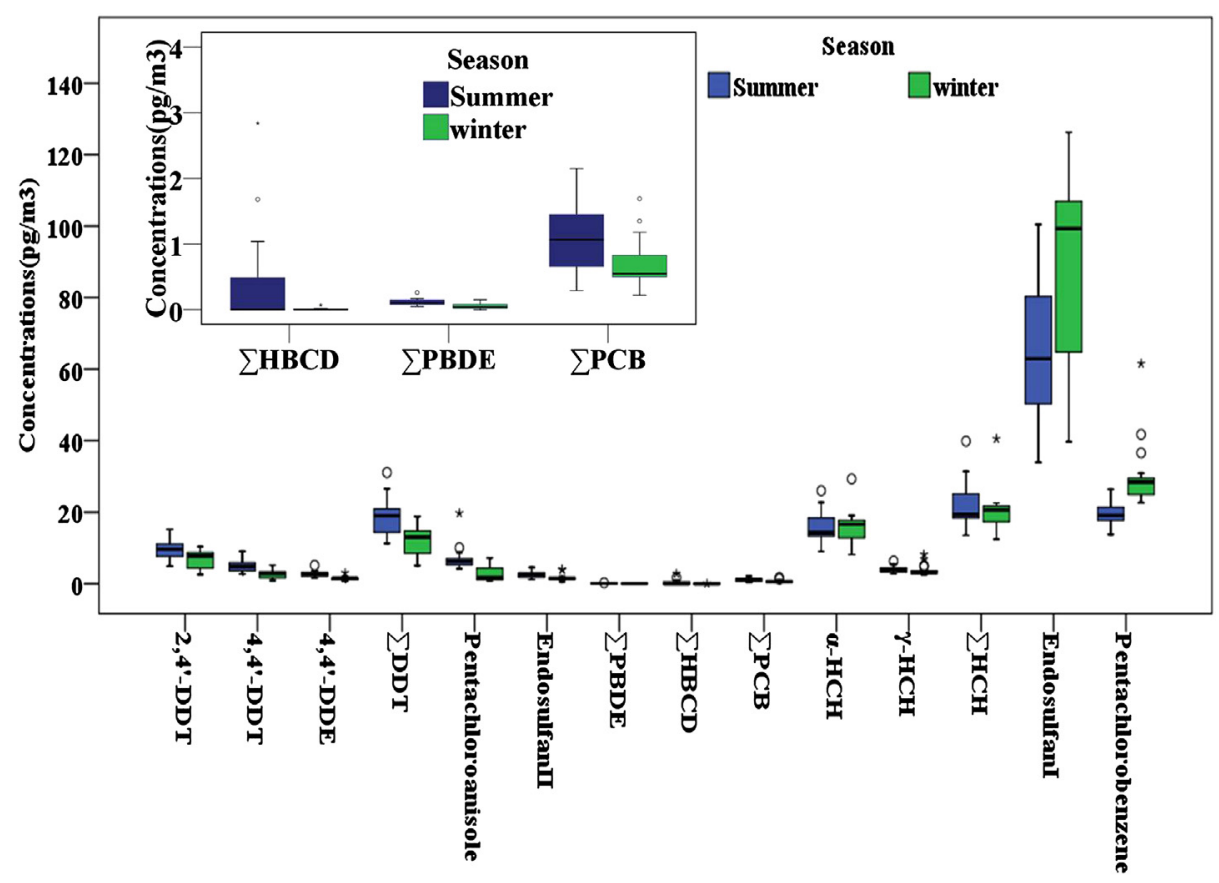

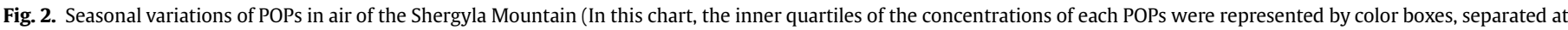

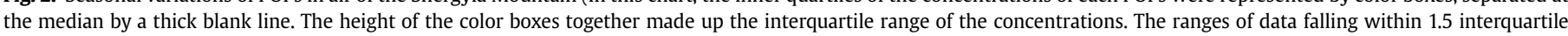

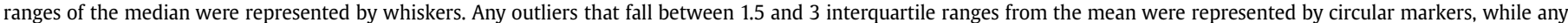

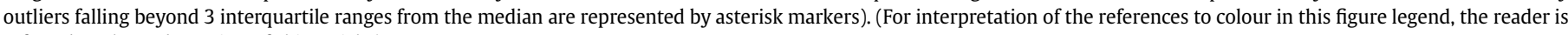
referred to the web version of this article.)

(Schmidt et al., 2001). The results implied no fresh input of endosulfan to the sampling areas recently.

Technical DDTs has been banned in China since 1983, but is still applied against mosquitoes in several countries, such as India, to control malaria (Bedi et al., 2013). Application of technical DDT and DDT-containing dicofol may be responsible for the DDTs occurrence in the environment. In the present work, The ratios of 2,4'-DDT/ $4,4^{\prime}$-DDT and DDT/(DDE + DDD) were used as indicators of source and aging of DDTs, based on the fact that ratio of $2,4^{\prime}$-DDT/4, $4^{\prime}$-DDT in technical DDT (0.2) is distinctly lower than the one in dicofol (7) (Qiu et al., 2005) and that DDT can be gradually transformed to the stable metabolites DDE and DDD (Willett et al., 1998). The ratios of $2,4^{\prime}$-DDT/4,4'-DDT in the air samples fell between the ones of technical DDT (0.2) and dicofol (7) and the ratios of DDT/ (DDD + DDE) were higher than 1, indicating that DDTs in the air of the Shergyla Mountain was probably atmospherically transported from source regions and jointly influenced by the fresh use of technical DDT and dicofol. The lower ratio of $4,4^{\prime}$-DDT/ $\left(4,4^{\prime}-\right.$ $\left.\mathrm{DDD}+4,4^{\prime}-\mathrm{DDE}\right)$ than $2,4^{\prime}-\mathrm{DDT} /\left(2,4^{\prime}-\mathrm{DDD}+2,4^{\prime}-\mathrm{DDE}\right)$ also confirmed the use of dicofol in the potential source region, as one of its major compounds $4,4^{\prime}-\mathrm{Cl}$-DDT can easily convert to $4,4^{\prime}$-DDE (Qiu et al., 2005).

Sources of HCHs in the environment mainly come from the use of technical HCHs (55-80\% $\alpha-\mathrm{HCH}, 5-14 \% \beta-\mathrm{HCH}, 8-15 \% \gamma-\mathrm{HCH}$, and $2-16 \% \delta-\mathrm{HCH})$ and lindane $(>99 \% \gamma-\mathrm{HCH}), \alpha-/ \gamma-\mathrm{HCH}$ is often used to apportion the pollution sources. The ratio values of $\alpha-\mathrm{HCH} /$ $\gamma-\mathrm{HCH}$ ranges from 3 to 7 in the technical HCHs but tends to increase over time due to the lower air-water partitioning coefficient $\left(\mathrm{K}_{\mathrm{AW}}\right)$ of $\gamma-\mathrm{HCH}$ compared to $\alpha-\mathrm{HCH}$ (Walker et al., 1999) and the photolytic isomerization from $\gamma-\mathrm{HCH}$ to $\alpha-\mathrm{HCH}$ during long range transport (Malaiyandi and Shah, 1984). However, continuous application of lindane would decrease the $\alpha-\mathrm{HCH} / \gamma-\mathrm{HCH}$ ratio in the environment. In the present study, the ratio of $\alpha-\mathrm{HCH} / \gamma-\mathrm{HCH}$ ranged from 2.0 to 6.9 , which indicated a combined source influence by technical HCHs and lindane in the sampling regions.
The PBDEs profile in the air samples of the Shergyla Mountain was quite different from the commercial formulations of pentaBDEs that usually consist of $24-38 \%$ tetra-BDEs, $50-60 \%$ pentaBDEs and 4-8\% hexa-BDEs (de Wit, 2002). Considering that BDE183 is an indicator congener of commercial octa-BDE (Song et al., 2004), the existence of PBDEs in this region could be due to the combined influence of commercial penta-BDEs and octa-BDEs. However, we cannot exclude the possibility of the influence of deca-BDEs as BDE-183 could also be a degradation compound of BDE-209 (Bezares-Cruz et al., 2004). The PCBs profile with higher proportion of lighter congeners in XADs was due to the facts that lighter PCBs have higher LRAT potential and XAD mainly accumulate semi-volatile organic compounds in the gas-phase of air since PCBs are prone to be partitioned in the gas phase. Owing to the high lipophilicities and low vapor pressures, HBCDs inclines to be absorbed to particulate matter and a relatively small fraction can be found in the gas phase. In the present study, the XAD-2 samples showed the gas-phase HBCDs level in the Shergyla Mountain was $0.25 \mathrm{pg} \mathrm{m}^{-3}$, which was higher than the level of PBDEs in the same region and to some extent reflected that the occurrence of airborne HBCDs might prevail in the environment. Its stereoisomeric profile dominated by $\gamma$-HBCD was similar to those of commercial HBCDs mixtures(commercial HBCDs mixtures mainly consist of 75-89\% $\gamma$ HBCD, $10-13 \% \alpha$-HBCD and 1-12\% $\beta$-HBCD (Peled et al., 1995)), particulate phase of air, soil and sediment (Ni and Zeng, 2013; Zhang et al., 2013).

Li et al. (Li et al., 2008) provided evidence of local emission of OCPs in Lhasa city of the Tibetan Plateau. However, the ratios of $2,4^{\prime}$-DDT/4,4'-DDT (4.24) and $\alpha-\mathrm{HCH} / \gamma-\mathrm{HCH}(0.27-0.37)$ in Lhasa city were quite different from the ones in the present work, suggesting the sources existing in Lhasa city were not responsible for the occurrence of OCPs in the Shergyla Mountain. Based the back trajectory result shown in the Fig. S1, Tibetan Plateau is mainly influenced by the Indian monsoon coming through south Asia (mainly northeast India) in summer and the southern branch of the 

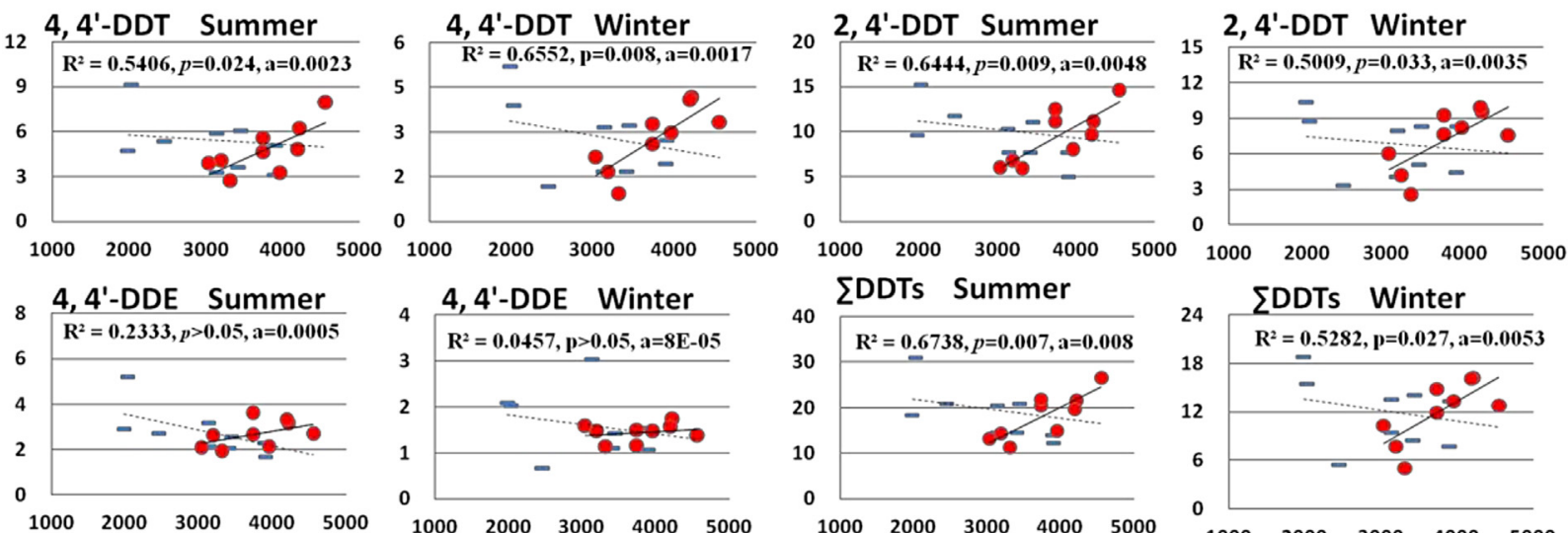

¿DDTs Summer

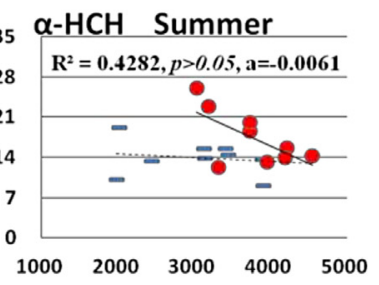

$\alpha-\mathrm{HCH}$ Winter
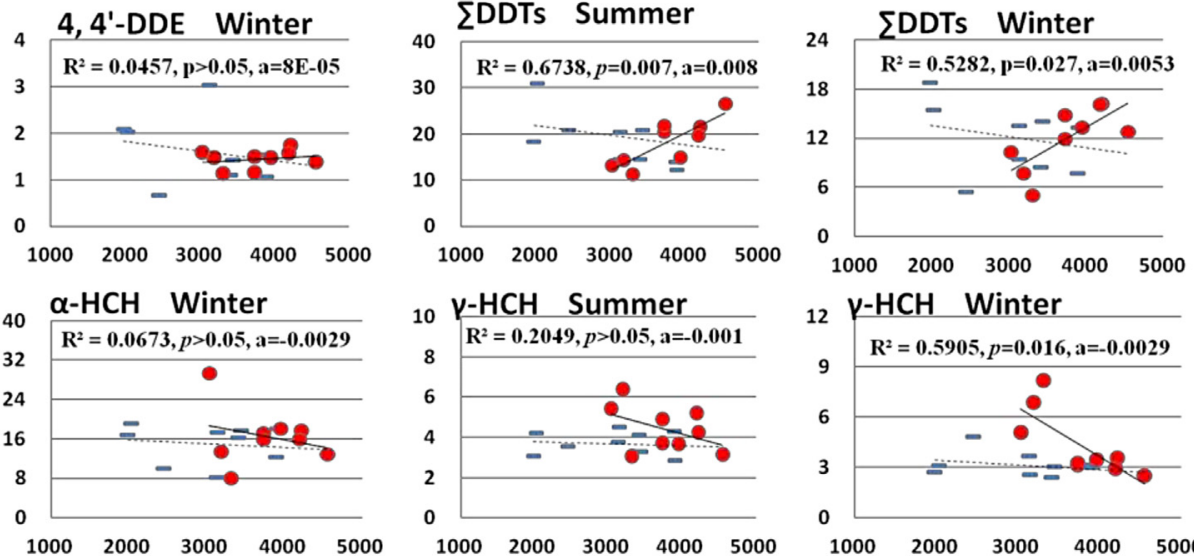

¿HCHs Summer
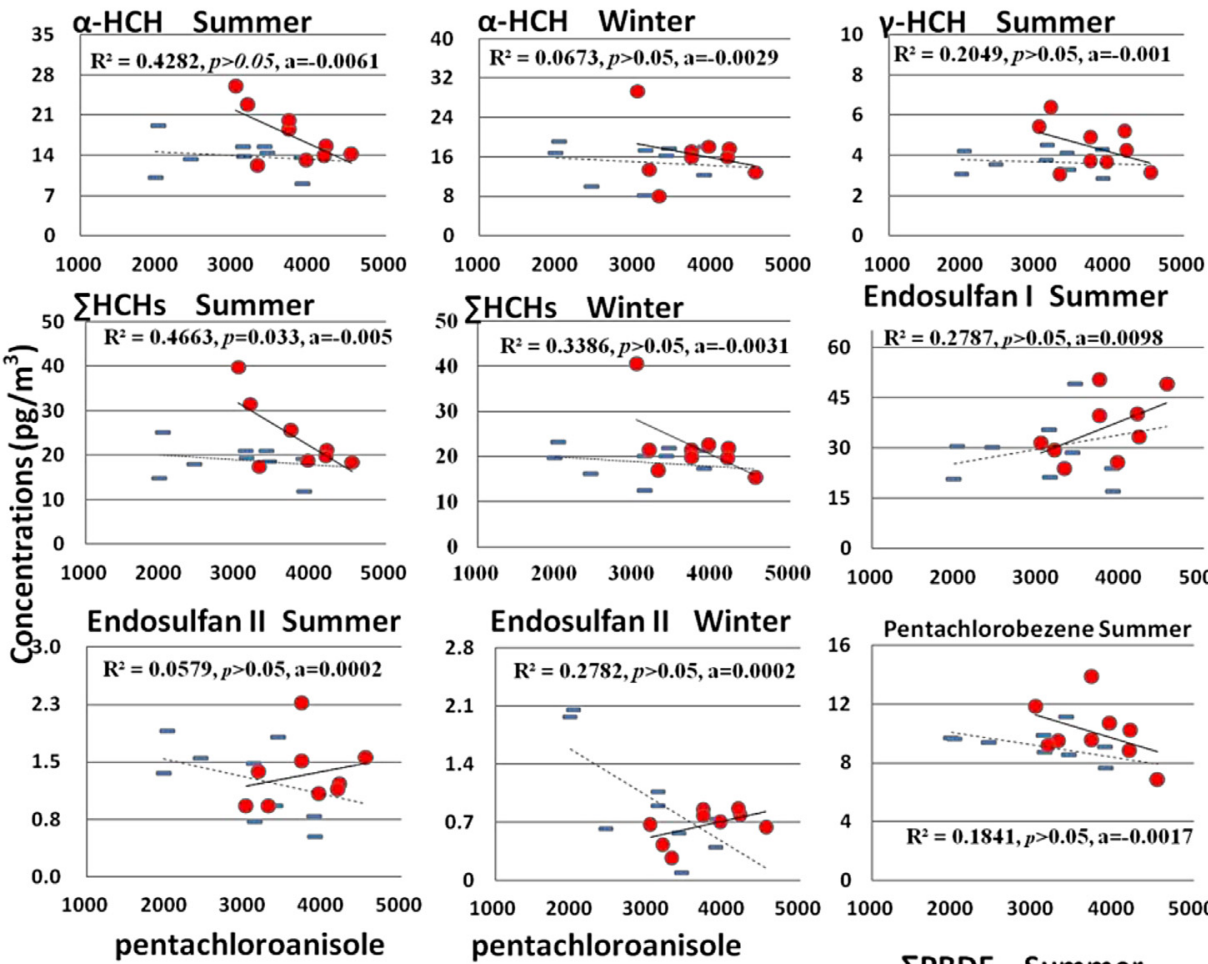

$12 \mathrm{~V}-\mathrm{HCH}$ Winter
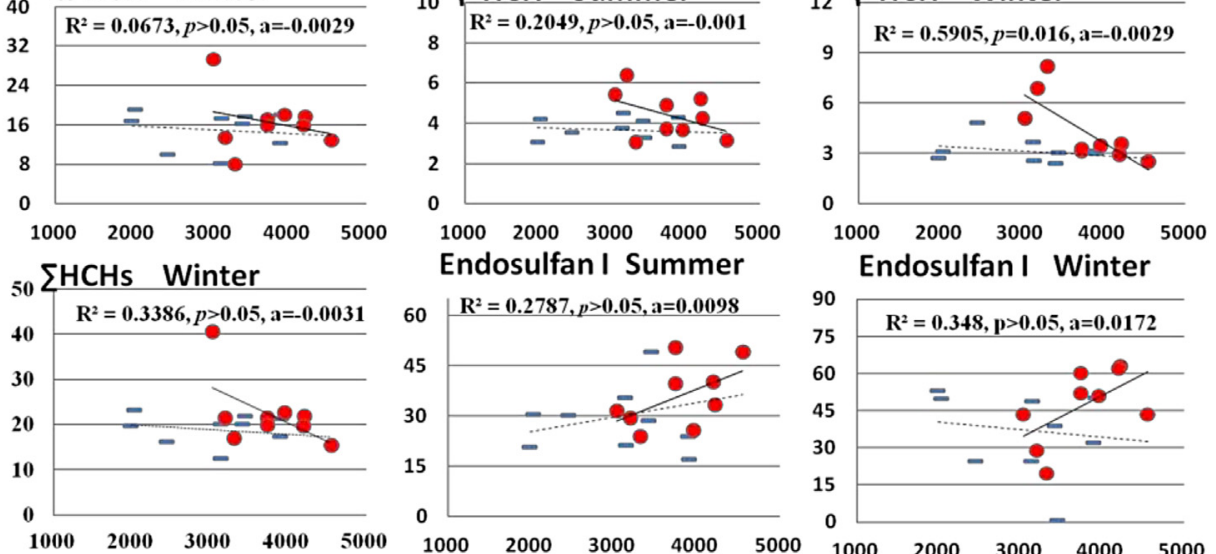

Endosulfan I Winter
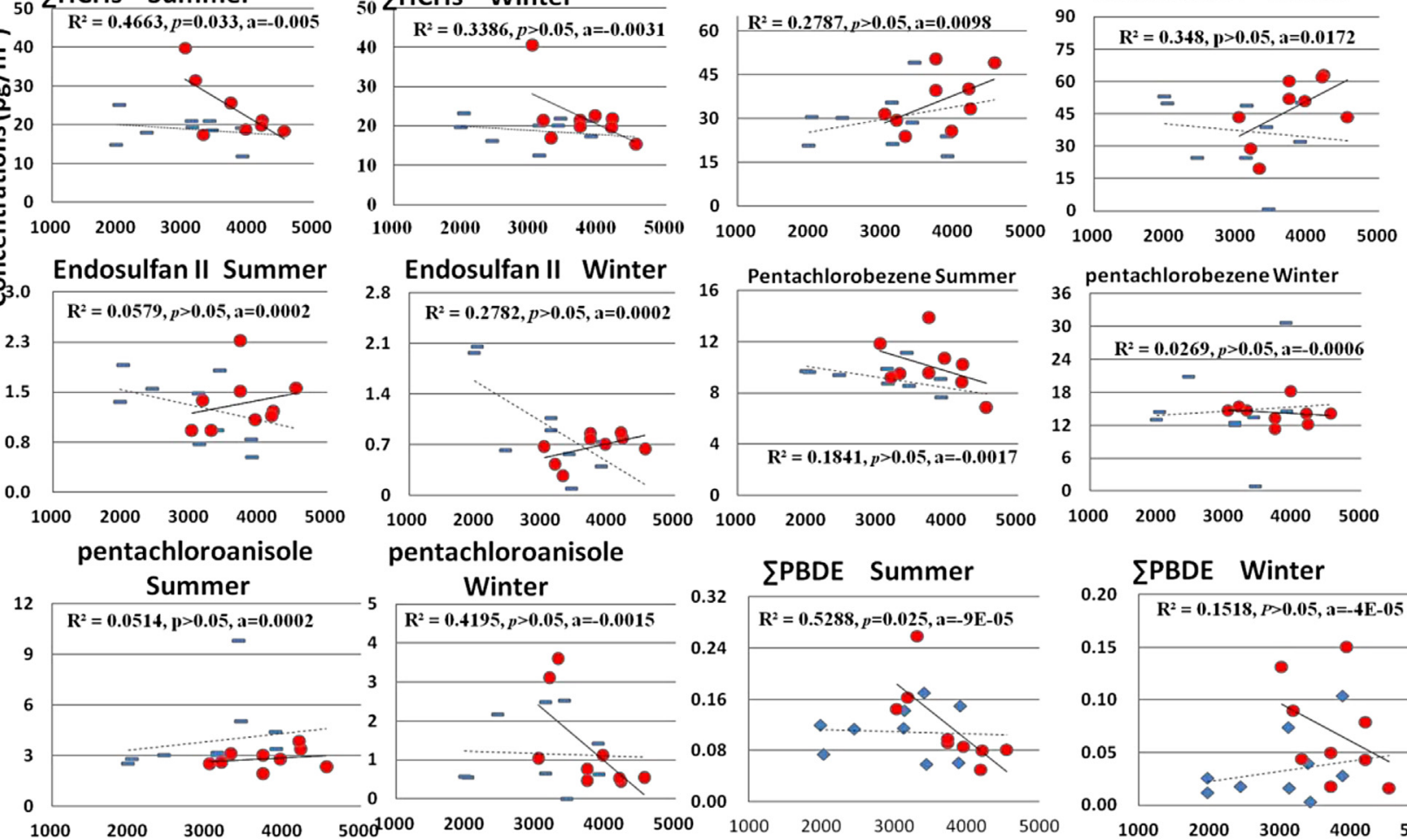

pentachloroanisole
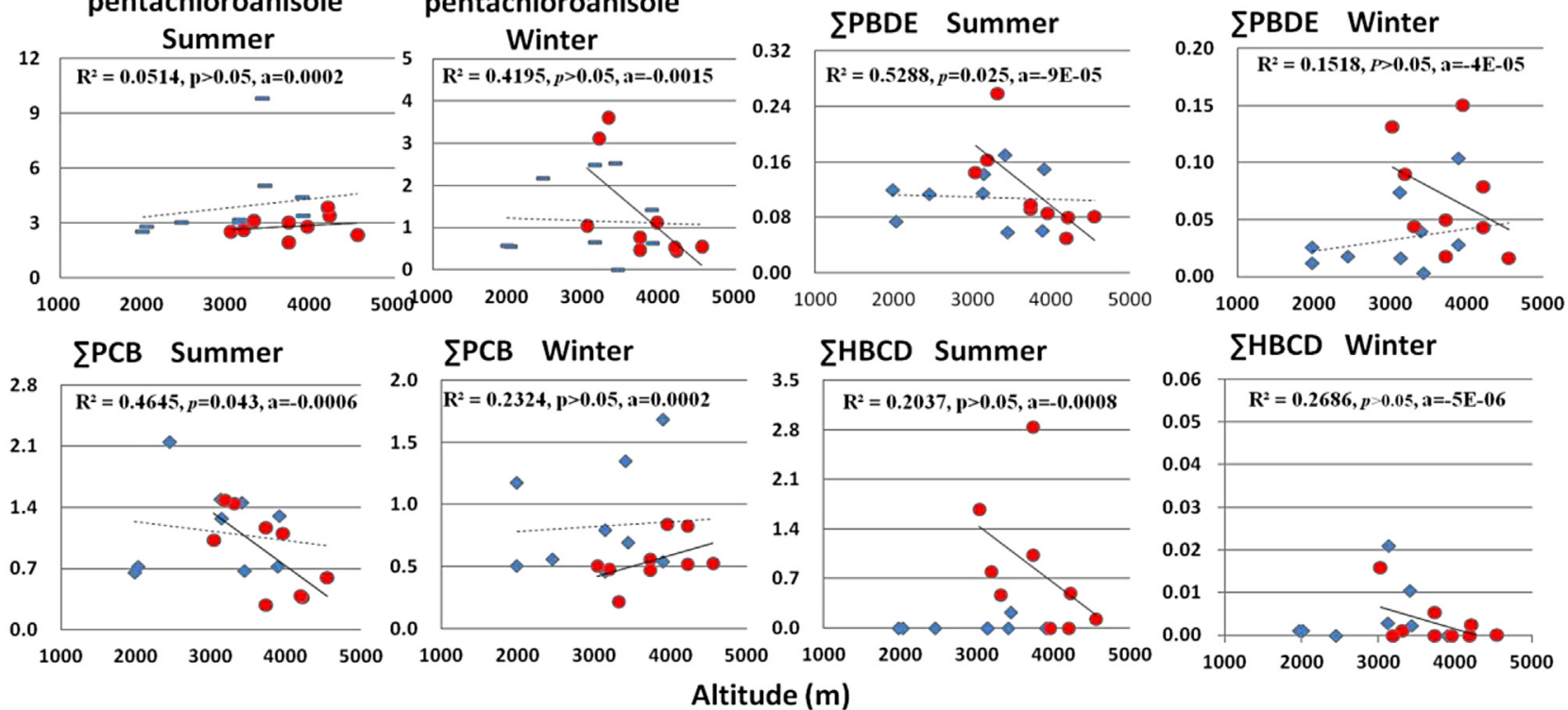

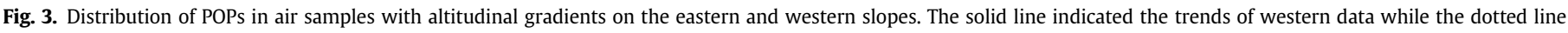

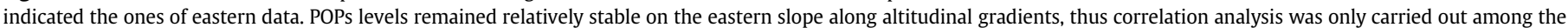
western data. In the data item, "a" means regression slope. 

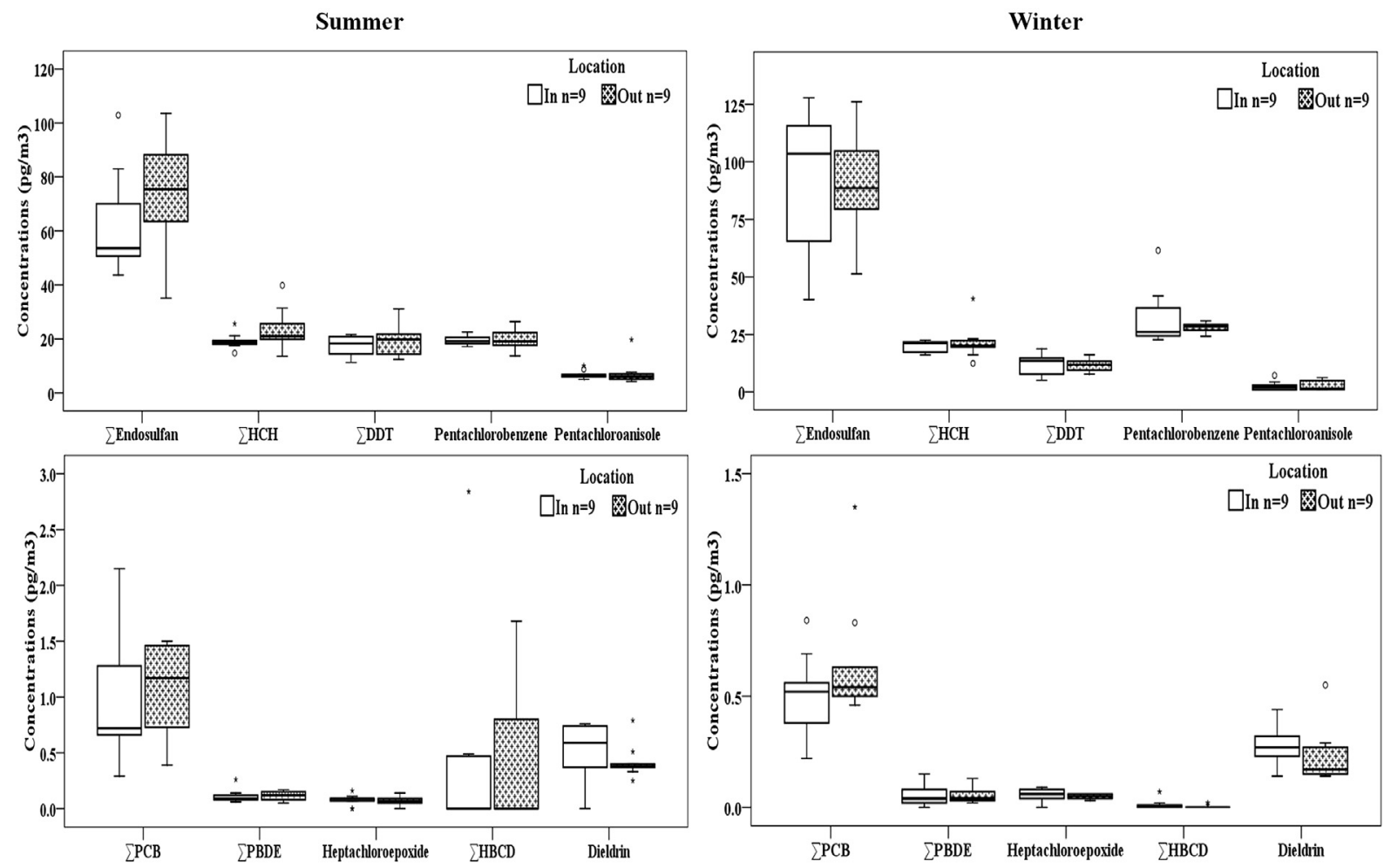

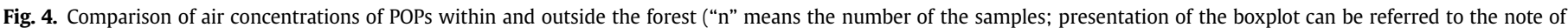
Fig. 2).

westerly that sweeps over the regions of southwest Asia, such as Pakistan-North India-Nepal in winter. In these countries, PCBs and PBDEs are continuously discharged through human activity, and OCPs such as DDTs and HCHs are still used for the agriculture application (Guzzella et al., 2005), which could be the potential important sources of POPs to the Tibetan Plateau transported by LRAT. Previous works also pointed out that in summer, the Indian monsoon not only brings water vapor to provide moisture and precipitation (Tian et al., 2007), but also carries on POPs, such as DDTs and PCBs, from India to the Tibetan Plateau (Wang et al., 2010; Sheng et al., 2013).

\subsection{Seasonality and slope variations of POPs}

Generally, the various occurrences of POPs in different seasons of pristine mountain were subjected to the influence of physicochemical characteristics of POPs, sources, temperature, prevailing air current and precipitation. Back trajectories analysis (Fig. S1) suggested target POPs in the Shergyla Mountain in summer and winter might mainly originate from two different regions (from south Asia, mainly northeast India, in summer and from southwest Asia, such as Pakistan-North India-Nepal in winter), which strengthened by the non-significant correlation $(p>0.05)$ between the air concentrations of POPs in the two seasons. Enhanced volatilization rates due to the increase of temperature in the summer, and the higher input of these compounds carried on by the Indian monsoon (Wang et al., 2010; Yang et al., 2008; Sheng et al., 2013) could be mainly responsible for the significantly (Paired-samples $T$ Test, $p<0.05$ ) higher concentrations of DDTs, pentachloroanisole, PBDEs, HBCDs and PCBs in summer than those in winter. The calculated $\log K_{\mathrm{OW}}$ of $\mathrm{HCH}$ is in the range of 3.72-4.14 (Estimation Program Interface Suite ${ }^{\mathrm{TM}}$, 2011), which made HCHs highly susceptible to the wet precipitation by gas scavenging in summer, thus counterbalance the influence of enhanced volatilization rates and input of HCHs in summer. This might be the main reason for the comparable levels in summer and winter. The reasons for the opposite trends of endosulfan I and endosulfan II in the seasonality variation remained unclear, but the variable ratio of endosulfan I/II in summer $(27.3 \pm 5.7)$ and winter $(61.6 \pm 19.3)$ suggested the possibility that different sources of endosulfan might exist in the two different seasons in the Shergyla Mountain.

Due to the influence of the large moisture passage of the Yarlung Tsangpo Valley on the eastern slope of the Shergyla Mountain, the turbulent water vapor transportation along the eastern slope might increase the mixing rates of POPs in the atmosphere and cause relatively uniform levels of POPs on the eastern slope (Fig. 3). Differently, the influence of water vapor transportation on the western slope was not obvious, and clear concentration gradients of POPs with altitude were obtained on the western slope. Current application status, volatilization from underlying surface, enhanced gas and particle scavenging caused by increased precipitation at higher elevations should, to some extent, jointly accounted for the different distributions of these POPs in the atmosphere of the western slope of the Shergyla Mountain. Since DDTs (Blais et al. 2003; Davidson et al., 2003; Shen et al., 2005) and endosulfan (Daly et al., 2007; Wania and Westgate, 2008) are particularly susceptible to mountain cold-trapping, the trend of increasing air concentrations of DDTs and endosulfans with altitude in the present work may reflect the re-volatilization of DDTs and endosulfans that had been cold-trapped at high mountain areas. The higher regression slope of $2,4^{\prime}$-DDT than the one of $4,4^{\prime}$-DDT indicated $2,4^{\prime}$-DDT exhibit higher potential of partitioning in colder condition experienced with altitude. A range of other researches also noted increasing air concentrations of endosulfan (Shunthirasingham et al., 2011) and other POPs (Loewen et al., 2008; Wania, 1999) with elevation and ascribed it to re-evaporation effect. Although 
the deposition of POPs increases with altitude, the capacity of high altitude environment to retain them decreases (sparse vegetation cover, lower organic matter in soil). As for HBCDs, there are no studies reporting local sources in Tibetan Plateau. The increasing particle scavenging of HBCDs along altitude might be the dominant factor that influenced the transport of HBCDs in high mountains and caused their decreasing concentration gradient with altitudes, since they are more prone to be absorbed on atmospheric particles due to their relatively low volatility and high octanol-air partition coefficient $\mathrm{K}_{\mathrm{OA}}$. Similarly, enhanced gas scavenging by increased precipitation at higher elevations should account for the decreasing concentration gradient of $\mathrm{HCHs}$ in the air against altitudes of Shergyla Mountain due to their low $\mathrm{K}_{\mathrm{OW}}$. Considering that the western slope was closer to the cities of Lhasa and Nyingchi and situated on the windward side of the westerly wind, the input of the air current near lower-land might be a primary factor influencing the concentration gradient of PBDEs, pentachlorobenzene and pentachloroanisole.

\subsection{Forest filter effect}

Forests can act as efficient filters for many airborne POPs (McLachlan and Horstmann, 1998). Their canopies can capture POPs on leaves and barks from air and redirect POPs to the soil by different processes: rain washout, wax erosion, and transport due to litter fall. In the present work, air concentrations of the most target POPs in the forest were lower than those in adjacent clearings (Fig. 4), especially in the summer, which indicated the existence of the potential forest filter effect for POPs in the Shergyla Mountain. Surface development of leaves was considered to determine the exchange of POPs between air and leaves (Jaward et al., 2005). Forests in the Shergyla Mountain are dominated by coniferous forests and coupled with broadleaf forest at the low altitudes. In the present work, the ratios of the forest:clearing concentrations of POPs at low altitudes $(<3300 \mathrm{~m})$ in summer were lower than those in winter. This was probably due to the fact that the broadleaf forest and the deciduous-coniferous forests have bigger leaf area in summer than in winter and thus having higher air-forest exchange flux. Similar forest filter effect was also observed by Jaward et al. (2005). In their results, ratios of the forest:clearing concentrations of POPs (PCBs, HCB and DDT) ranged from 0.54 to 0.93 at low altitudes ( $1000 \mathrm{~m}$ and $1400 \mathrm{~m}$ ) with broadleaf forests in both warmer and colder sampling periods, but were higher by about a factor of 2 at high altitude (1800) with conifer forests in the colder sampling period. And they considered the higher values than 2 might be related to the characterists of needle surfaces. In our present work, ratios of the forest:clearing concentrations of $\sum$ endosulfan were significantly different in the summer and the winter. Reasons for that remained unclear, but the ongoing use of endosulfan in nearby regions probably accounted for it.

\section{Conclusion}

This study explored the fate and behavior of mostly legacy POPs including OCPs and PCBs, and the emerging POPs, HBCDs and PBDEs, in the air of the Shergyla Mountain located in the Southeast Tibetan Plateau. Rising volatilization, cold-condensation, monsoon influence, enhanced gas and particle scavenging caused by increased precipitation, and vegetation, to some extent, accounted for the different distributions of POPs in the atmosphere of the sampling locations. Among the target POPs, DDTs and endosulfan showed increasing concentration gradients with altitude, implied the possible influence of their re-volatilization after being coldtrapped in the environmental matrices in the Shergyla Mountain.

\section{Acknowledgement}

This work was jointly supported by the National Natural Science Foundation (21177149, 21222702, 41101476).

\section{Appendix A. Supplementary data}

Supplementary data related to this article can be found at http:// dx.doi.org/10.1016/j.envpol.2014.04.031.

\section{References}

Baek, S.Y., Choi, S.D., Chang, Y.S., 2011. Three-year atmospheric monitoring of organochlorine pesticides and polychlorinated biphenyls in polar regions and the South Pacific. Environ. Sci. Technol. 45, 4475-4482.

Barber, J.L., Sweetman, A.J., van Wijk, D., Jones, K.C., 2005. Hexachlorobenzene in the global environment: emissions, levels, distribution, trends and processes. Sci. Total Environ. 349, 1-44.

Bedi, J.S., Gill, J.P.S., Aulakh, R.S., Kaur, P., Sharma, A., Pooni, P.A., 2013. Pesticide residues in human breast milk: risk assessment for infants from Punjab, India. Sci. Total Environ. 463, 720-726.

Bezares-Cruz, J., Jafvert, C.T., Hua, I., 2004. Solar photodecomposition of decabromodiphenyl ether: products and quantum yield. Environ. Sci. Technol. 38, 4149-4156

Blais, J.M., Wilhelm, F., Kidd, K.A., Muir, D.C., Donald, D.B., Schindler, D.W., 2003. Concentrations of organochlorine pesticides and polychlorinated biphenyls in amphipods (Gammarus lacustris) along an elevation gradient in mountain lakes of western Canada. Environ. Toxicol. Chem./SETAC 22, 2605-2613.

Botaro, D., Torres, J.P., Malm, O., Rebelo, M.F. Henkelmann, B., Schramm, K.W., 2011. Organochlorine pesticides residues in feed and muscle of farmed Nile tilapia from Brazilian fish farms. Food Chem. Toxicol. : Int. J. Publ. Br. Ind. Biol. Res. Assoc. 49, 2125-2130.

Brubaker Jr., W.W., Hites, R.A., 1998. OH reaction kinetics of gas-phase alpha-and gamma-hexachlorocyclohexane and hexachlorobenzene. Environ. Sci. Technol. 32, 766-769.

Cabrerizo, A., Dachs, J., Barcelo, D. Jones, K.C., 2012. Influence of organic matter content and human activities on the occurrence of organic pollutants in antarctic soils, lichens, grass, and mosses. Environ. Sci. Technol. 46, 1396-1405.

Cheng, H.R., Zhang, G., Jiang, J.X., Li, X.D., Liu, X., Li, j., Zhao, Y.C., 2007. Organochlorine pesticides, polybrominated biphenyl ethers and lead isotopes during the spring time at the Waliguan Baseline Observatory, northwest China: implication for long-range atmospheric transport. Atmos. Environ. 41, 47344747.

Daly, G.L., Wania, F., 2005. Organic contaminants in mountains. Environ. Sci. Technol. 39, 385-398.

Daly, G.L., Lei, Y.D., Teixeira, C., Muir, D.C., Castillo, L.E., Wania, F., 2007. Accumulation of current-use pesticides in neotropical montane forests. Environ. Sci. Technol. 41, 1118-1123.

Davidson, D.A., Wilkinson, A.C., Blais, J.M., Kimpe, L.E., McDonald, K.M., Schindler, D.W., 2003. Orographic cold-trapping of persistent organic pollutants by vegetation in mountains of western Canada. Environ. Sci. Technol. 37, 209-215.

de Wit, C.A., 2002. An overview of brominated flame retardants in the environment. Chemosphere 46, 583-624.

Eleni, L., Manolis, M., Euripides, G.S., 2009. Occurrence and diurnalvariation of polychlorinatedbiphenyls and polybrominateddiphenylethers in the background atmosphere of EasternMediterranean. Chemosphere 77, 1161-1167.

Estellano, V.H., Pozo, K., Harner, T., Franken, M., Zaballa, M., 2008. Altitudinal and seasonal variations of persistent organic pollutants in the Bolivian Andes Mountains. Environ. Sci. Technol. 42, 2528-2534.

Estimation Program Interface Suite, 2011. Suite Version 4.10. http://www.epa.gov/ oppt/exposure/pubs/episuite.htm.

Feng, J.Y., Wang, Y.W., Ruan, T., Qu, G.B., Jiang, G.B., 2010. Simultaneous determination of hexabromocyclododecanes and tris (2,3-dibromopropyl) isocyanurate using LC-APCI-MS/MS. Talanta 82, 1929-1934.

Gong, P., Wang, X.P., Sheng, J.J., Yao, T.D., 2010. Variations of organochlorine pesticides and polychlorinated biphenyls in atmosphere of the Tibetan Plateau: role of the monsoon system. Atmos. Environ. 44, 2518-2523.

Guzzella, L., Roscioli, C., Vigano, L., Saha, M., Sarkar, S., Bhattacharya, A., 2005. Evaluation of the concentration of HCH, DDT, HCB, PCB and PAH in the sediments along the lower stretch of Hugli estuary, West Bengal, northeast India. Environ. Int. 31, 523-534.

Hoh, E., Hites, R.A., 2005. Brominated flame retardants in the atmosphere of the east-central United States. Environ. Sci. Technol. 39, 7794-7802.

Jaward, F.M., Di Guardo, A., Nizzetto, L., Cassani, C., Raffaele, F., Ferretti, R., Jones, K.C., 2005. PCBs and selected organochlorine compounds in Italian mountain air: the influence of altitude and forest ecosystem type. Environ. Sci. Technol. 39, 3455-3463.

Li, J., Lin, T., Qi, S.H., Zhang, G., Liu, X., Li, K., 2008. Evidence of local emission of organochlorine pesticides in the Tibetan plateau. Atmos. Environ. 42, 73977404. 
Li, Y., Zhang, Q., Ji, D., Wang, T., Wang, Y., Wang, P., Ding, L., Jiang, G., 2009. Levels and vertical distributions of PCBs, PBDEs, and OCPs in the atmospheric boundary layer: observation from the Beijing 325-m meteorological tower. Environ. Sci. Technol. 43, 1030-1035.

Liu, W., Chen, D., Liu, X., Zheng, X., Yang, W., Westgate, J.N., Wania, F., 2010. Transport of semivolatile organic compounds to the Tibetan plateau: spatial and temporal variation in air concentrations in mountainous Western Sichuan, China. Environ. Sci. Technol. 44, 1559-1565.

Loewen, M., Wania, F., Wang, F., Tomy, G., 2008. Altitudinal transect of atmospheric and aqueous fluorinated organic compounds in western Canada. Environ. Sci. Technol. 42, 2374-2379.

Malaiyandi, M., Shah, S.M., 1984. Evidence of photoisomerization of hexachlorocycleohexane isomers in the ecosphere. J. Environ. Sci. Health Part AEnviron. Sci. Eng. Toxic Hazard. Subst. Control 19, 887-910.

McLachlan, M.S., Horstmann, M., 1998. Forests as filters of airborne organic pollutants: a model. Environ. Sci. Technol. 32, 413-420.

Ni, H.-G., Zeng, H., 2013. HBCD and TBBPA in particulate phase of indoor air in Shenzhen, China. Sci. total Environ. 458-460, 15-19.

Peled, M., Scharia, R., Sondack, D., 1995. Thermal rearrangement of hexabromocyclododecane (HBCD). Ind. Chem. Libr. 7, 92-99.

Pozo, K., Harner, T., Wania, F., Muir, D.C.G., Jones, K.C., Barrie, L.A., 2006. Toward a global network for persistent organic pollutants in air: results from the GAPS study. Environ. Sci. Technol. 40, 4867-4873.

Oiu, X.H., Zhu, T., Yao, B., Hu, J.X., Hu, S.W., 2005. Contribution of dicofol to the current DDT pollution in China. Environ. Sci. Technol. 39, 4385-4390.

Remberger, M., Sternbeck, J., Palm, A., Kaj, L., Stromberg, K., Brorstrom-Lunden, E., 2004. The environmental occurrence of hexabromocyclododecane in Sweden. Chemosphere 54, 9-21.

Schmidt, W.F., Bilboulian, S., Rice, C.P., Fettinger, J.C., McConnell, L.L., Hapeman, C.J. 2001. Thermodynamic, spectroscopic, and computational evidence for the irreversible conversion of beta- to alpha-endosulfan. J. Agric. Food Chem. 49, 5372-5376.

Schrlau, J.E., Geiser, L., Hageman, K.J., Landers, D.H., Simonich, S.M., 2011. Comparison of lichen, conifer needles, passive air sampling devices, and snowpack as passive sampling Media to measure semi-volatile organic compounds in remote atmospheres. Environ. Sci. Technol. 45, 10354-10361.

Shen, L., Wania, F., Lei, Y.D., Teixeira, C., Muir, D.C., Bidleman, T.F., 2005. Atmospheric distribution and long-range transport behavior of organochlorine pesticides in North America. Environ. Sci. Technol. 39, 409-420.

Shen, L., Wania, F., Lei, Y.D., Teixeira, C., Muir, D.C.G., Xiao, H., 2006. Polychlorinated biphenyls and polybrominated diphenyl ethers in the North American atmosphere. Environ. Pollut. 144, 434-444.

Sheng, J., Wang, X., Gong, P., Joswiak, D.R., Tian, L., Yao, T., Jones, K.C., 2013. Monsoon-driven transport of organochlorine pesticides and polychlorinated biphenyls to the Tibetan Plateau: three year atmospheric monitoring study. Environ. Sci. Technol. 47, 3199-3208.

Shunthirasingham, C., Barra, R., Mendoza, G., Montory, M., Oyiliagu, C.E., Lei, Y.D., Wania, F., 2011. Spatial variability of atmospheric semivolatile organic compounds in Chile. Atmos. Environ. 45, 303-309.

Song, W., Ford, J.C., Li, A., Mills, W.J., Buckley, D.R., Rockne, K.J., 2004. Polybrominated diphenyl ethers in the sediments of the Great Lakes. 1. Lake Superior. Environ. Sci. Technol. 38, 3286-3293.

Su, Y., Hung, H., Blanchard, P., Patton, G.W., Kallenborn, R., Konoplev, A., Fellin, P., Li, H., Geen, C., Stern, G., Rosenberg, B., Barrie, L.A., 2006. Spatial and seasonal variations of Hexachlorocyclohexanes (HCHs) and hexachlorobenzene (HCB) in the Arctic atmosphere. Environ. Sci. Technol. 40, 6601-6607.
Su, Y., Hung, H., Sverko, E., Fellin, P., Li, H., 2007. Multi-year measurements of polybrominated diphenyl ethers (PBDEs) in the Arctic atmosphere. Atmos. Environ. 41, 8725-8735.

Tian, L., Yao, T., MacClune, K., White, J., Schilla, A., Vaughn, B., Vachon, R. Ichiyanagi, K., 2007. Stable isotopic variations in west China: a consideration of moisture sources. J. Geophys. Res. Atmos. 112, 1984-2012.

Walker, K., Vallero, D.A., Lewis, R.G., 1999. Factors influencing the distribution of lindane and other hexachlorocyclohexanes in the environment. Environ. Sci. Technol. 33, 4373-4378.

Wang, X.p., Xu, B.q., Kang, S.c., Cong, Z.y., Yao, T.d., 2008. The historical residue trends of DDT, hexachlorocyclohexanes and polycyclic aromatic hydrocarbons in an ice core from Mt. Everest, central Himalayas, China. Atmos. Environ. 42 6699-6709.

Wang, P., Zhang, Q., Wang, Y., Wang, T., Li, X., Li, Y., Ding, L., Jiang, G., 2009. Altitude dependence of polychlorinated biphenyls (PCBs) and polybrominated diphenyl ethers (PBDEs) in surface soil from Tibetan Plateau, China. Chemosphere 76, $1498-1504$.

Wang, X.P., Gong, P., Yao, T.D., Jones, K.C., 2010. Passive air sampling of organochlorine pesticides, polychlorinated biphenyls, and polybrominated diphenyl ethers across the Tibetan Plateau. Environ. Sci. Technol. 44, 2988-2993.

Wania, F., 1999. On the origin of elevated levels of persistent chemicals in the environment. Environ. Sci. Pollut. Res. 6, 11-19.

Wania, F., Westgate, J.N., 2008. On the mechanism of mountain cold-trapping of organic chemicals. Environ. Sci. Technol. 42, 9092-9098.

Wania, F., Shen, L., Lei, Y.D., Teixeira, C., Muir, D.C.G., 2003. Development and calibration of a resin-based passive sampling system for monitoring persistent organic pollutants in the atmosphere. Environ. Sci. Technol. 37, 1352-1359.

Weber, J., Halsall, C.J., Muir, D., Teixeira, C., Small, J., Solomon, K., Hermanson, M., Hung, H., Bidleman, T., 2010. Endosulfan, a global pesticide: a review of its fate in the environment and occurrence in the Arctic. Sci. total Environ. 408, 29662984.

Willett, K.L., Ulrich, E.M., Hites, R.A., 1998. Differential toxicity and environmenta fates of hexachlorocyclohexane isomers. Environ. Sci. Technol. 32, 2197-2207.

Xiao, H., Shen, L. Su, Y.S., Barresi, E, DeJong M., Hung, H.L, Lei, Y. W. Wania, F, Reiner, E.J., Sverko, E., Kang, S.C., 2012. Atmospheric concentrations of halogenated flame retardants at two remote locations: the Canadian High Arctic and the Tibetan Plateau. Environ. Pollut. 161, 154-161.

Yang, R.Q., Yao, T.D., Xu, B.Q., Jiang, G.B., Zheng, X.Y., 2008. Distribution of organochlorine pesticides (OCPs) in conifer needles in the southeast Tibetan Plateau. Environ. Pollut. 153, 92-100.

Zhang, G. Chakraborty, P. Li, J., Sampathkumar, P. Balasubramanian, T., Kathiresan, K., Takahashi, S., Subramanian, A., Tanabe, S., Jones, K.C., 2008. Passive atmospheric sampling of organochlorine pesticides, polychlorinated biphenyls, and polybrominated diphenyl ethers in urban, rural, and wetland sites along the coastal length of India. Environ. Sci. Technol. 42, 8218-8223.

Zhang, Y.W., Ruan, Y.F., Sun, H.W., Zhao, L.J., Gan, Z.W., 2013. Hexabromocyclododecanes in surface sediments and a sediment core from Rivers and Harbor in the northern Chinese city of Tianjin. Chemosphere 90, 16101616.

Zheng, X., Chen, D., Liu, X., Zhou, Q., Liu, Y., Yang, W., Jiang, G., 2010. Spatial and seasonal variations of organochlorine compounds in air on an urban-rural transect across Tianjin, China. Chemosphere 78, 92-98.

Zhu, N., Li, A., Wang, T., Wang, P., Qu, G., Ruan, T., Fu, J., Yuan, B., Zeng, L., Wang, Y., Jiang, G., 2012. Tris(2,3-dibromopropyl) isocyanurate, hexabromocyclododecanes, and polybrominated diphenyl ethers in Mollusks from Chinese Bohai Sea. Environ. Sci. Technol. 46, 7174-7181. 